\title{
Analisa Karakteristik Campuran Aspal Beton Dengan Filler Yang Berbeda Terhadap Nilai Marshall
}

\section{Characteristic Analysis Of Asphalt Concrete Mixture With Different Fillers On Marshall Value}

\author{
*Muhammad Rasyad Tahir Dalimunthe, Melloukey Ardan \\ Program Studi Teknik Sipil, Fakultas Teknik \\ Universitas Medan Area, Indonesia \\ e-mail : rasyadst05@gmail.com \\ Diterima: April 2019; Disetujui: Mei 2019; Dipublish: Mei 2019
}

\begin{abstract}
Abstrak
Kondisi lapis permukaan suatu ruas jalan dengan menggunakan perkerasan lentur memiliki masalah dalam kerusakanya, yang penyebab utamanya berhubungan dengan kualitas bahan pendukungnya antara lain aspal dan agregat. Kerusakan akan cepat terjadi jika perkerasan tersebut mengalami pembebanan secara berlebihan dan pengaruh lingkungan, salah satunya temperatur yang relatif tinggi. Salah satu cara dalam mengatasi kerusakan jalan yang terjadi lebih awal adalah dengan memperbaiki kinerja campuran yaitu memodifikasi dengan cara menggunakan bahan tambah. Dengan nilai penetrasi yang rendah dan temperatur di Indonesia yang cukup tinggi absuton cocok digunakan sebagai bahan tambah. Penelitian sebelumnya menunjukkan dengan penambahan absuton butir dalam campuran mempunyai kecendrungan memperbaiki kinerja lapis perkerasan jalan terhadap pembebanan. Tujuan penelitian ini adalah mengetahui pola hubungan variasi campuran dengan filler batu kapur dengan filler semen portland untuk mengetahui kadar aspal optimum terhadap nilai karakteristik marshall. Penelitian ini menggunakan metode eksperimental yang dilakukan di laboratorium dengan aspal beton campuran filler yang berbeda dengan masing masing 5\%,5,5\%,6,\%,6,5 dan 7\%. Benda uji masing masing 20 buah. Pengujian menggunakan marshall test dengan hasil campuran filler semen lah yang lebih baik untuk aspal ketimbang filler batu kapur.
\end{abstract}

Kata Kunci : Aspal, filler Batu Kapur, Semen Portland, Marshall

\begin{abstract}
The surface layer condition of a road segment using flexible pavement has the problem of damage, the main cause of which is related to the quality of the supporting material such as asphalt and aggregate. Damage will occur quickly if the pavement is overloaded and environmental influences, one of which is relatively high temperature. One way to deal with early road damage is to improve mixed performance by modifying it by using added materials. With a low penetration value and temperature in Indonesia is quite high. Absuton suitable for use as an ingredient. Previous research has shown that the addition of grain absolutes in the mixture has a tendency to improve the performance of pavement layers against loading. The purpose of this research is to know the pattern of mixed variation relationship with limestone filler with portland cement filler to determine the optimum bitumen content of marshall characteristic value. This research used experimental method done in laboratory with mixed asphalt concrete mixer with 5\%, 5,5\%, 6,\%, 6,5 and 7\% respectively. 20 test pieces each. Testing using marshall test with the result of cement filler mixture is better for asphalt than lime filler.
\end{abstract}

Key Words: Asphalt, Lime filler, Portland Cement, Marshall

How to Cite: Dalimunthe,M,R,T, Melloukey,A dan Marwan,L (2019), Analisa Karakteristik Campuran Aspal Beton Dengan Filler Yang Berbeda Terhadap Nilai Marshall. JCEBT Uournal of Civil Engineering, Building and Transportation). 3 (1): 19-26 


\section{PENDAHULUAN}

Aspal beton atau asphaltic concrete adalah campuran dari agregat bergradasi menerus dengan bahan bitumen. Kekuatan utama aspal beton ada pada keadaan butir agregat yang saling mengunci dan sedikit pada pasir/filler/bitumen sebagai mortar. Pengalaman para pembuat aspal beton mengatakan bahwa campuran ini sangat stabil tetapi sangat sensitif terhadap variasi dalam pembuatannya dan perlu tingkat quality control yang tinggi dalam pembuatannya, bila potensinya ingin penuh terealisasi (Didik Purwadi, 1995).

Agregat terdiri dari pasir, gravel, batu pecah, slag atau material lain dari bahan mineral alami atau buatan. Agregat merupakan bagian terbesar dari campuran aspal. Material agregat yang digunakan untuk konstruksi perkerasan jalan tugas utamanya untuk menahan beban lalu lintas. Agregat dari bahan batuan pada umumnya masih diolah lagi dengan mesin pemecah batu (stone crusher) sehingga didapatkan ukuran sebagaimana dikehendaki dalam campuran. Agar dapat digunakan sebagai campuran aspal, agregat harus lolos dari berbagai uji yang telah ditetapkan. Bahan pengisi dapat terdiri atas debu batu kapur, debu dolomite, semen Portland, abu terbang, debu tanur tinggi pembuat semen atau bahan mineral tidak plastis lainnya. Bahan pengisi yang merupakan mikro agregat ini harus lolos saringan No. 200 $(0,075 \mathrm{~mm})$. Dari sekian banyak jenis bahan pengisi maka kapur padam banyak digunakan dari pada Portland semen. Portland semen mudah diperoleh dan mempunyai grading butiran yang bagus namun demikian harganya sangat mahal. Fungsi Filler dalam campuran aspal beton antara lain :

a. Memodifikasi gradasi agregat halus, sehingga campuran menjadi lebih rapat gradasinya.

b. Bersama-sama dengan aspal membentuk bahan pengikat atau sistem filler aspal. c. Penambahan kadar filler pada sistem aspal, filler akan menurunkan angka penetrasi.

d. Penambahan kadar filler akan memperbaiki ketahanan campuran aspal terhadap temperatur tinggi.

Filler meningkatkan ketahanan campuran aspal terhadap cuaca. Penguatan oleh filler berarti dapat menambah ketahanan terhadap retak. Ketahanan terhadap retak akan mencegah kerusakan yang disebabkan oleh pemuaian dan kontraksi akibat panas dan penyusutan aspal akibat adanya perubahan reaksi kimia-fisika selama berada dalam pengaruh cuaca. Rancangan campuran berdasarkan metode Marshall ditemukan oleh Bruce Marshall, dan telah distandarisasi oleh ASTM ataupun AASHTO melalui beberapa modifikasi, yaitu ASTM D 1559-76, atau AASHTO T-245-90. Prinsip dasar metode Marshall adalah pemeriksaan stabilitas dan kelelehan (flow), serta analisis kepadatan dan pori dari campuran padat yang terbentuk.

Agregat

Agregat dapat digolongkan dalam 2 kategori:

1. Agregat dari batuan beku (volcanic rock): agregat ini terjadi akibat pendinginan dan pembekuan dari bahan-bahan yang meleleh akibat panas (magma bumi).

Agregat ini digolongkan dalam 2 jenis pokok:

a. Agregat dari batuan ekstrusif: terjadinya akibat dilempar ke udara dan mendingin secara cepat. Jenis pokoknya: pyolite, andesite dan basalt. Sifat utamanya: berbutir halus, keras dan cenderung rapuh.

b. Agregat dari batuan intrusif: terjadinya akibat batuan yang mendingin secara lambat dan diperoleh sebagai singkapan. Jenis pokoknya: granit, diorit dan gabro. Sifat utamanya: berbutir kasar, keras dan kaku.

2. Agregat dari batuan endapan (sedimentary rock): agregat terjadi dari hasil endapan halus dari hasil pelapukan batuan bebas, tumbuh-tumbuhan, binatang. Dengan mengalami proses pelekatan dan 
penekanan oleh alam maka menjadi agregat/batuan endapan. Jenis agregat dari batuan endapan antara lain: batuan kapur, batuan silika dan batuan pasir.

1.) Pit atau bank run materials (pit-run), biasanya gravel dari ukuran $75 \mathrm{~mm} \mathrm{(3}$ inchi) sampai ukuran $4.75 \mathrm{~mm}$ (No. 4). Pasir yang terdiri partikel ukuran 4.75 mm (No. 4) hingga partikel berukuran $0.075 \mathrm{~mm}$ (No. 200). Ada juga silt yang berukuran $0.075 \mathrm{~mm}$ kebawah. Batubatuan tersebut tersingkap dan terdegradasi oleh alam baik secara fisik maupun kimiawi. Produk proses degradasi ini kemudian diangkut oleh angin, air atau es (gletser yang bergerak) dan diendapkan disuatu lahan.

2.) Agregat hasil proses, merupakan hasil proses pemecahan batu-batuan dengan stone-crusher machine (mesin pemecah batu) dan disaring. Agregat alam biasanya dipecah agar dapat digunakan sebagai campuran aspal. Agregat yang dipecah tersebut kualitasnya kemungkinan bertambah, dimana pemecahan akan merubah tekstur permukaan, merubah bentuk agregat dari bulat ke bersudut, menambah distribusi dan jangkauan ukuran partikel agregat. Pemecahan batu bisa dari ukuran bedrocks atau batu yang sangat besar. Pada ukuran bedrocks sebelum masuk mesin stonecrusher maka pengambilannya melalui blasting (peledakan dengan dinamit).

Agregat sintetis / buatan ( synthetic / artificial aggregates ), sebagai hasil modifikasi, baik secara fisik atau kimiawi. Agregat demikian merupakan hasil tambahan pada proses pemurnian biji tambang besi atau yang spesial diproduksi atau diproses dari bahan mentah yang dipakai sebagai agregat. Terak dapur tinggi (blast-furnace slag) adalah yang paling umum digunakan sebagai agregat buatan. Terak yang mengapung pada besi cair adalah bukan bahan logam (non-metallic), kemudian ukurannya diperkecil dan didinginkan dengan udara. Pemakaian agregat sintetis untuk pelapisan lantai jembatan, karena agregat sintetis lebih tahan lama dan lebih tahan terhadap geseran dari pada agregat alam.

Agregat Kasar

Fraksi agregat kasar untuk agregat ini adalah agregat yang tertahan di atas saringan 2,36 mm (No.8), menurut saringan ASTM. Fraksi agregat kasar untuk keperluan pengujian harus terdiri atas batu pecah atau kerikil pecah dan harus disediakan dalam ukuran-ukuran normal. Agregat kasar ini menjadikan perkerasan lebih stabil dan mempunyai skid resistance (tahanan terhadap selip) yang tinggi sehingga lebih menjamin keamanan berkendara. Agregat kasar yang mempunyai bentuk butiran (particle shape) yang bulat memudahkan proses pemadatan, tetapi rendah stabilitasnya, sedangkan yang berbentuk menyudut (angular) sulit dipadatkan tetapi mempunyai stabilitas yang tinggi. Agregat kasar harus mempunyai ketahanan terhadap abrasi bila digunakan sebagai campuran wearing course, untuk itu nilai Los Angeles Abrasion Test harus dipenuhi. Agregat Halus

Agregat halus adalah agregat hasil pemecah batu yang mempunyai sifat lolos saringan No.8 $(2,36 \mathrm{~mm})$ tertahan saringan No.200 (0,075 mm). Fungsi utama agregat halus adalah untuk menyediakan stabilitas dan mengurangi deformasi permanen dari perkerasan melalui keadaan saling mengunci (interlocking) dan gesekan antar butiran. Untuk hal ini maka sifat eksternal yang diperlukan adalah angularity (bentuk menyudut) dan particle surface roughness (kekasaran permukaan butiran).

Ukuran Agregat

Ukuran agregat dalam suatu campuran beraspal terdistribusi dari yang berukuran besar sampai ke yang kecil. Semakin besar ukuran maksimum agregat yang dipakai semakin banyak variasi ukurannya dalam campuran tersebut.

Gradasi Agregat

Gradasi agregat adalah distribusi dari ukuran 21 
terhadap total beratnya. Gradasi ditentukan dengan melewatkan sejumlah material melalui serangkaian saringan dari ukuran besar ke ukuran kecil dan menimbang berat material yang tertahan pada masing-masing saringan. Kombinasi gradasi agregat campuran dinyatakan dalam persen berat agregat. Untuk keperluan penelitian ini, maka dipilih kombinasi agregat yang sesuai dengan dibawah. Gradasi agregat dalam diambil dari spesifikasi agregat campuran dari 3 fraksi agregat.

Bahan Bitumen

Bitumen adalah zat perekat (cementitious) berwarna hitam atau gelap, yang dapat diperoleh di alam ataupun sebagai hasil produksi. Bitumen terutama mengandung senyawa hidrokarbon seperti aspal, tar, atau pitch.

Aspal didefinisikan sebagai material perekat (cementitious), berwarna hitam atau coklat tua, dengan unsur utama bitumen. Aspal dapat diperoleh di alam ataupun merupakan residu dari pengilangan minyak bumi. Tar adalah material berwarna coklat atau hitam, berbentuk cair atau semipadat, dengan unsur utama bitumen sebagai hasil kondensat dalam destilasi destruktif dari batu bara, minyak bumi, atau mineral organic lainnya. Pitch didefinisikan sebagai material perekat (cementitious) padat, berwarna hitam atau coklat tua, yang berbentuk cair jika dipanaskan. Pitch diperoleh sebagai residu dari destilasi fraksional tar. Pitch dan tar tidak diperoleh dari di alam, tetapi merupakan produk kimiawi. Dari ketiga material pengikat di atas, aspal merupakan material yang umum digunakan untukbahan pengikat agregat, oleh karena itu seringkali bitumen disebut juga sebagai aspal.

Aspal adalah material yang pada temperatur ruang berbentuk padat sampai agak padat, dan bersifat termoplastis. Jadi aspal akan mencair jika dipanaskan sampai temperatur tertentu, dan kembali membeku jika temperatur turun. Bersama dengan agregat, aspal merupakan material pembentuk campuran perkerasan jalan.
Banyaknya aspal dalam campuran perkerasan berkisar antara $4-10 \%$ berdasarkan berat campuran, atau $10-15 \%$ berdasarkan volume campuran.

Berdasarkan tempat diperolehnya, aspal dibedakan menjadi 2 macam yaitu

Aspal Alam

Aspal alam adalah aspal yang didapat di suatu tempat di alam, dan dapat digunakan sebagaimana diperolehnya atau dengan sedikit pengolahan. Aspal alam ada yang diperoleh di gunung-gunung seperti aspal di Pulau Buton yang disebut dengan Asbuton. Asbuton merupakan batu yang mengandung aspal. Asbuton merupakan campuran antara bitumen dengan bahan mineral lainnya dalam bentuk batuan. Karena asbuton merupakan material yang ditemukan begitu saja di alam, maka kadar bitumen yang dikandungnya sangat bervariasi dari rendah sampai tinggi. Untuk mengatasi hal ini, maka asbuton mulai diproduksi dalam berbagai bentuk di pabrik pengolahan asbuton.

Aspal Minyak

Aspal minyak adalah aspal yang merupakan residu destilasi minyak bumi. Setiap minyak bumi dapat menghasilkan residu jenis asphaltic base crude oil yang banyak mengandung aspal, paraffin base crude oil yang banyak mengandung parafin, atau mixed base crude oil yang mengandung campuran antara parafin dan aspal. Untuk perkerasan jalan umumnya digunakan aspal minyak jenis asphaltic base crude oil.

Residu aspal berbentuk padat, tetapi melalui pengolahan hasil residu ini dapat pula berbentuk cair atau emulsi pada suhu ruang. Aspal padat adalah aspal yang berbentuk padat atau semipadat pada suhu ruang dan menjadi cair jika dipanaskan. Aspal padat dikenal dengan nama semen aspal (asphalt cement). Aspal cair (cutback asphalt) yaitu aspal yang berbentuk cair pada suhu ruang. Aspal cair merupakan semen aspal yang dicairkan dengan bahan pencair dari hasil penyulingan minyak bumi seperti minyak tanah, bensin, atau solar. Aspal emulsi (emulsified asphalt) adalah suatu campuran 
aspal dengan air dan bahan pengemulsi, yang dilakukan di pabrik pencampur. Aspal emulsi lebih cair daripada aspal cair.

Metode Perencanaan Campuran

Rancangan campuran bertujuan untuk mendapatkan resep campuran aspal beton dari material yang terdapat di lokasi sehingga dihasilkan campuran yang memenuhi spesifikasi campuran yang ditetapkan. Saat ini, metode rancangan campuran yang paling banyak dipergunakan di Indonesia adalah metode rancangan campuran berdasarkan pengujian empiris, dengan menggunakan alat Marshall.

Aspal Beton

Aspal beton adalah jenis perkerasan jalan yang terdiri dari campuran agregat dan aspal, dengan atau tanpa bahan tambahan. Lapis aspal beton merupakan jenis tertinggi dari perkerasan yang merupakan campuran dari bitumen dengan agregat bergradasi menerus dan cocok untuk jalan yang banyak dilalui kendaraan berat. Material-material pembentuk aspal beton dicampur dan diinstalasi pencampur pada suhu tertentu, kemudian diangkut ke lokasi, dihamparkan, dan dipadatkan. Suhu pencampuran ditentukan berdasarkan jenis aspal yang akan digunakan. Jika digunakan semen aspal, maka suhu pencampuran umumnya antara 145\%155으 C, sehingga disebut aspal beton campuran panas. Campuran ini dikenal juga dengan nama hotmix.

Aspal beton harus memiliki karakteristik dalam pencampuran yaitu stabilitas, keawetan atau durabilitas, kelenturan atau fleksibilitas, ketahanan terhadap kelelahan (fatigue resistance), kekesatan permukaan atau ketahanan geser, kedap air, dan kemudahan pelaksanaan. Ketujuh sifat aspal beton ini tidak mungkin dapat dipenuhi sekaligus oleh satu jenis campuran. Sifat-sifat aspal beton mana yang dominan lebih diinginkan, akan menentukan jenis aspal beton yang dipilih. Hal ini sangat perlu diperhatikan ketika merancang tebal perkerasan jalan. Jalan yang melayani lalu lintas ringan, seperti mobil penumpang, sepantasnya lebih memilih jenis aspal beton yang mempunyai sifat durabilitas dan fleksibilitas yang tinggi, daripada memilih jenis aspal beton dengan stabilitas tinggi.

Metode Marshall

Rancangan campuran berdasarkan metode Marshall ditemukan oleh Bruce Marshall, dan telah distandarisasi oleh ASTM ataupun AASHTO melalui beberapa modifikasi, yaitu ASTM D 1559-76, atau AASHTO T-245-90. Prinsip dasar metode Marshall adalah pemeriksaan stabilitas dan kelelehan (flow), serta analisis kepadatan dan pori dari campuran padat yang terbentuk.

Alat Marshall merupakan alat tekan yang dilengkapi dengan proving ring

(cincin penguji) berkapasitas 22,2 KN (5000 lbs) dan flowmeter. Proving ring digunakan untuk mengukur nilai stabilitas, dan flowmeter untuk mengukur kelelehan plastis atau flow. Benda uji Marshall berbentuk silinder berdiameter 4 inchi $(10,2 \mathrm{~cm})$ dan tinggi 2,5 inchi $(6,35 \mathrm{~cm})$. Prosedur pengujian Marshall mengikuti SNI 06-2489-1991, atau AASHTO T 245-90, atau ASTM D 1559-76.

Secara garis besar pengujian Marshall meliputi: persiapan benda uji, penentuan berat jenis bulk dari benda uji, pemeriksaan nilai stabilitas dan flow, dan perhitungan sifat volumetric benda uji.

\section{METODE PENELITIAN}

Penelitian ini dilakukan di laboratorium PT.Adhi Karya Perkasa dengan dasar menggunakan sistem pencampuran aspal panas Asphalt Concrete - Wearing Course (ACWC). Dan dilakukan pada waktu 5-18 juni 2017. Jenis data di bagi atas data primer dan skunder dari hasil di lab ADHI KARYA dengan campuran filler batu kapur dan filler semen. Bahan-bahan yang akan digunakan dalam penelitian ini antara lain:

1) Agregat kasar, diperoleh dari hasil pemecahan batu (stone crusher) dari AMP PT. Adhi Karya Perkasa di Patumbak.

2) Begitu pula untuk bahan pengisi (filler) yang digunakan adalah semen portland 
dari PT. Adhi Karya Perkasa di Patumbak.

3) Agregat halus pasir dan abu batu yang diperoleh dari PT. Adhi Karya.

4) Filler lain sebagai bahan perbandingan adalah batu kapur yang diambil dari PT. Adhi Karya.

5) Untuk bahan aspal menggunakan aspal PERTAMINA dengan penetrasi 60/70.

\begin{tabular}{lll}
\hline NO & $\begin{array}{l}\text { COLD BIN } \\
\text { DESCRIPTION }\end{array}$ & $\begin{array}{l}\text { COMBINED } \\
(\%)\end{array}$ \\
\hline \hline 1 & COARSE & 19 \\
& AGGREGATE & \\
2 & MEDIUM & 24 \\
3 & AGGREGATE & 47.1 \\
4 & DUST STONE & 8 \\
5 & NATURAL SAND & 1.9 \\
& FILLER & $\mathbf{1 0 0}$ \\
\hline
\end{tabular}

Tabel 1:Komposisi Material

Sumber :Data Lapangan Lab PT. Adhi Karya

Peralatan Penelitian

1) lain: alat uji penetrasi, alat uji titik lembek, alat uji titik nyala dan titik bakar, alat uji daktilitas, alat uji berat jenis (piknometer dan timbangan), alat uji kelarutan (CCl4).

2) Alat uji pemeriksaan agregat

Alat uji yang digunakan untuk pemeriksaan agregat antara lain mesin Los Angeles (tes abrasi), saringan standar (yang terdiri dari ukuran 3/4", 1/2", 3/8", \#4, \#8, \#16, \#30, \#50 dan \#200), alat uji kepipihan, alat pengering (oven), timbangan berat, alat uji berat jenis (piknometer, timbangan, pemanas), bak perendam dan tabung sand equivalent.

3) Alat uji karakteristik campuran agregat aspal. Alat uji yang digunakan adalah seperangkat alat untuk metode Marshall,meliputi:

a) Alat tekan Marshall yang terdiri kepala penekan berbentuk lengkung, cincin penguji berkapasitas $3000 \mathrm{~kg}$ (5000lb) yang dilengkapi dengan arloji pengukur flowmeter.

b) Alat cetak benda uji berbentuk silinder diameter 10,2cm (4inch) dengan tinggi 7,5cm (3inch) untuk Marshall standar.

c) Penumbuk manual yang mempunyai permukaan rata berbentuk silinder dengan diameter $9,8 \mathrm{~cm}$, berat $4,5 \mathrm{~kg}$ (10lb) dengan tinggi jatuh bebas $45,7 \mathrm{~cm}$ (18inch).

d) Ejektor untuk mengeluarkan benda uji setelah proses pemadatan.

e) Bak perendam yang dilengkapi pengatur suhu.

4) Alat uji pemeriksaan aspal, Alat yang digunakan untuk pemeriksaan aspal antara lain: alat uji penetrasi, alat uji titik lembek, alat uji titik nyala dan titik bakar, alat uji daktilitas, alat uji berat jenis (piknometer dan timbangan), alat uji kelarutan (CCl4).

5) Alat uji pemeriksaan agregat, Alat uji yang digunakan untuk pemeriksaan agregat antara lain mesin Los Angeles (tes abrasi), saringan standar (yang terdiri dari ukuran 3/4", 1/2", 3/8", \#4, \#8, \#16, \#30, \#50 dan \#200), alat uji kepipihan, alat pengering (oven), timbangan berat, alat uji berat jenis (piknometer, timbangan, pemanas), bak perendam dan tabung sand equivalent.

6) Alat uji karakteristik campuran agregat aspal. Alat uji yang digunakan adalah seperangkat alat untuk metode Marshall,meliputi:

f) Alat tekan Marshall yang terdiri kepala penekan berbentuk lengkung, cincin penguji berkapasitas $3000 \mathrm{~kg}$ (5000lb) yang dilengkapi dengan arloji pengukur flowmeter.

g) Alat cetak benda uji berbentuk silinder diameter 10,2cm (4inch) dengan tinggi $7,5 \mathrm{~cm}$ (3inch) untuk Marshall standar.

h) Penumbuk manual yang mempunyai permukaan rata berbentuk silinder 
dengan diameter $9,8 \mathrm{~cm}$, berat $4,5 \mathrm{~kg}$ (10lb) dengan tinggi jatuh bebas $45,7 \mathrm{~cm}$ (18inch).

i) Ejektor untuk mengeluarkan benda uji setelah proses pemadatan.

j) Bak perendam yang dilengkapi pengatur suhu.

k) Alat-alat penunjang yang meliputi panci pencampur, kompor pemanas, termometer, kipas angin, sendok pengaduk, kaos tangan anti panas, kain lap, kaliper, spatula, timbangan dan tip-ex/cat minyak yang digunakan untuk menandai benda uji.

Prosedur Perencanaan Penelitian

Untuk menentukan kadar aspal optimum diperkirakan dengan penentuan Garis Pemotong antara VIM Marshall dengan VIM PRD. Ditentukan 2 (dua) kadar aspal di atas dan 2 (dua) kadar aspal dengan kadar filler yang sama. Sebelum menentukan kadar aspal optimum harus dibuat terlebih dahulu benda uji dengan variasi kadar aspal rencan yaitu 5,0\%; 5,5\%; 6,0\%; 6,5\%; 7,0\%. Kemudian dilakukan penyiapan benda uji untuk tes Marshall sesuai tahapan berikut ini :

a. Tahap I

Berdasarkan variasi kadar aspal rencana 5,0\%; 5,5\%; 6,0\%; 6,5\%; 7,0\% benda uji dibuat dengan komposisi filler yang sama antara semen portlan dan semen portland $1,9 \%$, untuk menentukan komposisi agregat terlebih dahulu agregat harus digradasi untuk mencari SPGR setiap agaregat agar dapat menetukan komposisi masing-masing agregat. Setelah diketahui komposisi agregat barulah bisa dibuat benda ujinya dengan masing-masing tiga benda uji pada setiap kadar aspal rencana. Kemudian dilakukan pengujian Marshall standar dengan 2x75 tumbukan dan pengujian durabilitas untuk menentukan VIM, VMA, VFA, kepadatan, stabilitas, kelelehan, dan hasil bagi Marshall(MQ).

b. Tahap II

Untuk mencari kadar aspal optimum terlebih dahulu harus mencari nilai VIM dari kepadatan mutlak 2x400 tumbukan. Karena untuk mencari kadar aspal optimum dengan cara memotong garis VIM Marshall dengan nilai maksimal 5 dan memotong garis VIM PRD dengan nilai minimum 2, setelah didapat nilai dari garis yang memotong VIM Marshal dan VIM PRD nilainya ditambhakan lalu dibagi 2 dan itulah nilai kadar aspal optimumnya.

c. Tahap III

Setelah didapat nilai kadar aspal optimum dilanjut dengan mencari nilai Marshall Sisa atau keawetan umur aspal dengan pengujian lama rendaman, yang pertama lama rendaman 30 menit dan yang kedua lama rendaman 24 jam dengan nilai kadar aspal optimum yang telah didapat. Kemudian ditest dengan alat uji marshall untuk menentukan VIM, VMA, VFA, stabilitas, kelelehan, dan hasil bagi Marshall (MQ) dari kadar aspal optimum.

Komposisi Material

Alat-alat penunjang yang meliputi panci pencampur, kompor pemanas, termometer, kipas angin, sendok pengaduk, kaos tangan anti panas, kain lap, kaliper, spatula, timbangan dan tip-ex/cat minyak yang digunakan untuk menandai benda uji.

\section{HASIL DAN PEMBAHASAN}

Dalam perencanaan variasi kadar aspal dalam campuran, pedoman dalam perhitungan ini mengikuti standartd dari Laboratorium PT. Adhi Karya. Dalam penelitian ini variasi kadar aspal rencananya adalah 5\%, 5,5\%, 6\%, 6,5\%, 7\%. Proses pengujian Marshall dapat dilakukan setelah seluruh persyaratan material, berat jenis, penyerapan aspal dan perkiraan kadar aspal rencana telah terpenuhi. Diperlukan juga tabel angka koreksi d an kalibrasi pada alat uji tekan Marshall dalam perhitungan stabilitas marshall. Dari kedua percobaan ini hasil uji marshall dengan lama perendaman dan kadar aspal optimum dapat diketahui nilai stability dan berat jenis yang paling tinggi adalah dengan menggunakan filler semen portland dengan nilai 2,278 gr/cc dan 1105 kg. 


\section{SIMPULAN}

Pengujian Material Aspal

Penggunaan aspal Pen 60 disesuaikan dengan kondisi suhu udara rata-rata $25^{\circ} \mathrm{C}$. Metode pengujian aspal sesuai Spesifikasi Umum Bina Marga 2010 dengan mengacu pada SNI 06-6399-2000 dengan ketentuan pada Tabel 3.5.

Dari hasil penelitian benda uji perbandingan antara filler batu kapur dengan filler semen portland dalam campuran Asphalt Concrete - Wearing Course (ac - wc) terhadap karakteristik marshall.Pada uji Marshall dengan kadar aspal rencana seluruh sifat sifat Marshall yang didapatkan mempunyai hasil yang hampir sama untuk masing masing campuran dengan dua macam jenis filler batu kapur dan semen portland.Hasil untuk kadar aspal rencana pada berat jenis dan stabilitas dapat disimpulkan semakin tinggi kadar aspalnya maka semakin tinggi nilai stabilitasnya. Untuk filler batu kapur terhadap pengaruh campuran ac-wc memenuhi persyaratan dalam standard Spesifikasi Umum Bina Marga 2010 Revisi 3 yaitu $1095 \mathrm{~kg}$ dengan batas minimum untuk nilai stabilitas $800 \mathrm{~kg}$. Untuk perbandingan Marshall sisa dari kadar aspal optimum yang berbeda dengan test marshall dapat disimpulkan bahwa penggunaan semen portland sebagai filler dalam campuran ac-wc menghasilkan nilai stabilitas dan berat jenis yang lebih baik dibandingkan dengan batu kapur dengan nilai stabilitas $1180 \mathrm{~kg} \geq 1095$ $\mathrm{kg}$.

\section{DAFTAR PUSTAKA}

Departemen Pekerjaan Umum, Pekerjaan Lapis Pondasi Jalan, Buku 1 Umum, Manual Konstruksi dan Bangunan, Direktorat Jendral Bina Marga, (2006).

Departemen Pekerjaan Umum, Pekerjaan Lapis Pondasi Jalan, Buku 3 Lapis Pondasi Agregat, Manual Konstruksi dan
Bangunan, Direktorat Jendral Bina Marga, (2006).

Departemen Pekerjaan Umum, Pekerjaan Lapis Pondasi Jalan, Buku 8 Permasalahan Lapangan, Manual Konstruksi dan Bangunan, Direktorat Jendral Bina Marga, (2006).

Departemen Pekerjaan Umum, Petunjuk Pelaksanaan Lapisan Atas Aspal Beton (Laston), Direktorat Jendral Bina Marga, (2010).

Direktorat Pembinaan Jalan Kota.(1990). Tata Cara Penyusunan Pemeliharaan Jalan Kota (No. 018/T/BNKT/1990), Direktorat Jendral Bina Marga Departemen PU. Jakarta.

Dapertemen Pekerjaan Umum Badan Penerbit Pekerjaan Umum Rencana Campuran (Mix Design) bagian A (Teori Gradasi) untuk Beton Aspal, Aspal Mastik, Base \& Sub Base Course Beton P.C, (2006).

Hary Christady Hardiayatmo "Pemeliharaan Jalan Raya" November (2015)

Ir. Hotman Marpaung "Beton dan Pengujian", Medan, (2000).

Sukirman silvia "Beton Aspal Campuran Panas" Jakarta April (2003)

Sukirman Silvia "Perkerasan lentur jalan raya", Bandung, Bandung (1999). 
JCEBT (Journal of Civil Engineering, Building and Transportation), 3(1) Maret 2019 : 19-26 